\title{
IDIOPATHIC PULMONARY HYPERTENSION
}

\author{
BY \\ DONALD HEATH,* WILLIAM WHITAKER, AND JAMES W BROWN

\begin{abstract}
From The Regional Cardiovascular Unit The City General Hospital and the University Department of Medicine, The Royal Hospital, Sheffield

Received February 23, 1956
\end{abstract}

Since it became possible to record pulmonary artery blood pressures directly by cardiac catheterization, several authors have described severe pulmonary arterial hypertension in patients without any apparent predisposing cause such as a septal defect or mitral stenosis. The purpose of the present communication is to describe four further patients with idiopathic pulmonary hypertension and to emphasize that the clinical features and pathological lesions in the lungs of these cases are similar to those occurring in other patients with severe pulmonary hypertension secondary to congenital septal defects. Heath and Whitaker (1956) have pointed out that all patients with severe pulmonary hypertension present a distinct clinico-pathological entity, which they term hypertensive pulmonary vascular disease; it is dominated in life by the symptoms and signs of pulmonary hypertension and characterized at autopsy by specific changes in the small pulmonary blood vessels.

\section{CASE REPORTS}

The clinical picture in all four cases was strikingly similar and was dominated in each instance by the classical signs of pulmonary arterial hypertension. These were giant $a$ waves in the jugular venous pulse (Fig. 4), a parasternal heave, a systolic lift over the right ventricular outflow tract, and a palpable second sound in the pulmonary area which was loud and split on auscultation. All were in congestive cardiac failure. In each case the electrocardiogram showed right ventricular hypertrophy and peaked $P$ waves suggestive of right auricular hypertrophy (Fig. 1), while the teleradiogram showed overall cardiac enlargement (Fig. 2). which erroneously seemed on fluoroscopy to be due to left ventricular hypeztrophy (Fig. 3). In all there was increased prominence of the pulmonary artery and expansile pulsation of its main branches not amounting to a hilar dance (Fig. 2 and 3). In none were the peripheral vessels of the lung clearly seen. In Cases 1 and 4 angiocardiography confirmed the aneurysmal enlargement of the pulmonary arteries and the absence of a congenital cardiac anomaly (Fig. 2). The flow of blood through the lungs in both was sluggish and eight seconds after injection no contrast medium had appeared in the left side of the heart. Cardiac catheterization demonstrated severe pulmonary arterial hypertension (Fig. 4) in Case 1, 2, 3, and 4 and no evidence of an intracardiac shunt. In each case the radial pulse was normal or of poor volume, while the systemic blood pressure was normal or low (Fig. 4).

Similarly, in each of the cases that came to necropsy (Cases 1,2, and 3) certain histological changes in the pulmonary blood vessels occurred constantly (Fig. 5). The pulmonary arterioles $(<100 \mu$ in external diameter), which in normal human lung consist of a single elastic lamina lying between the endothelium and a thin adventitia, showed a distinct muscular media between two elastic laminæ, a thickened adventitia, and severe intimal fibrosis (Fig. 5). The muscular pulmonary arteries (100-1000 $\mu$ in external diameter) had a thickened adventitia and severe intimal fibrosis but in

* Leverhulme Research Scholar, Royal College of Physicians 


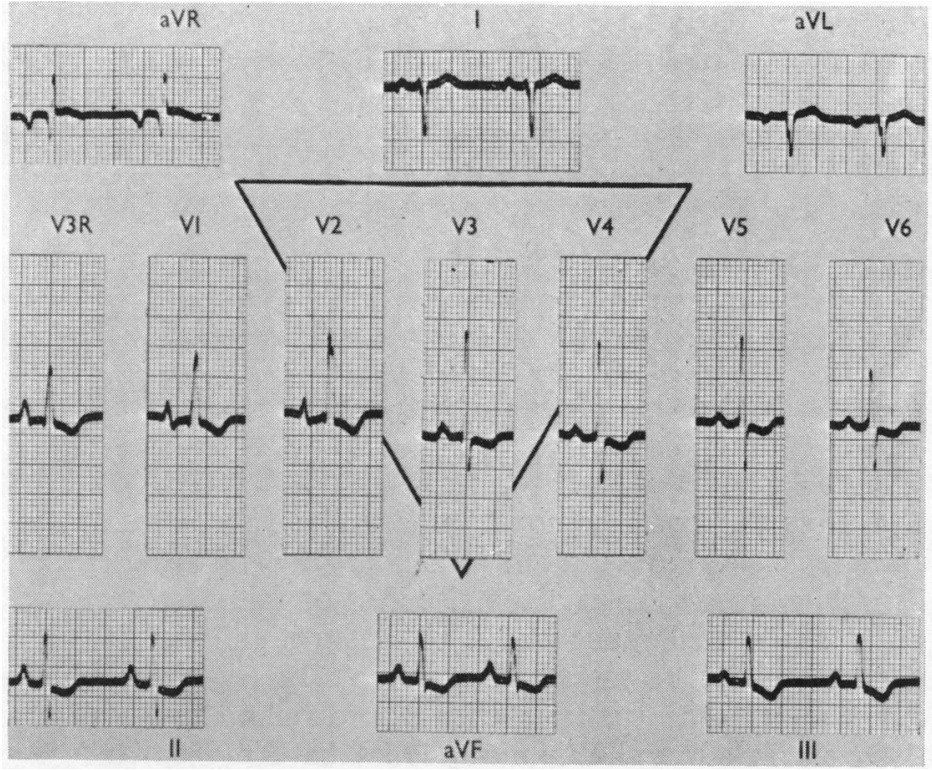

FiG. 1.-Electrocardiogram, showing right axis deviation, right ventricular hypertrophy, and clockwise rotation of a vertical heart. Case 4.

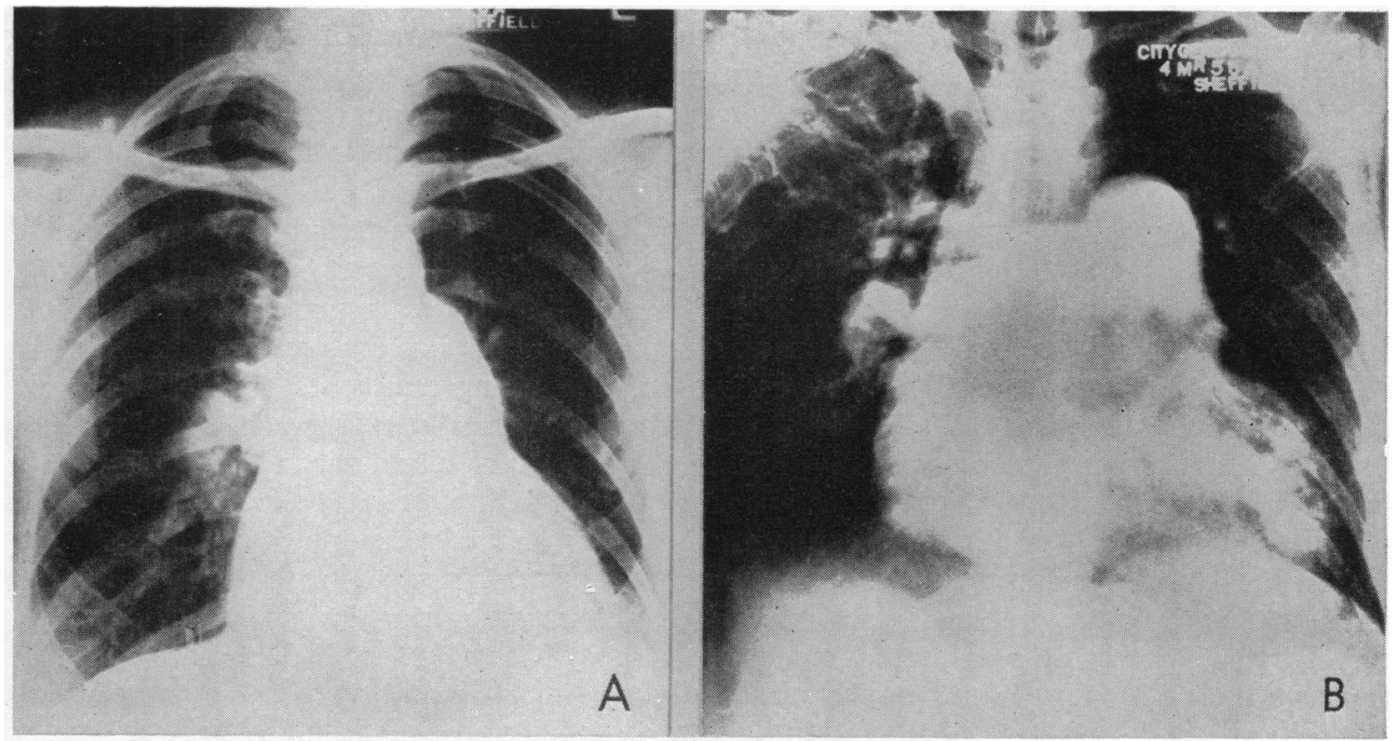

Fig. 2.-(A) Postero-anterior teleradiogram, showing moderate overall cardiac enlargement with prominence of the pulmonary trunk and its main branches. (B) Postero-anterior angiocardiogram taken 8 seconds after injection of the contrast medium, showing the retention of the dye in the dilated pulmonary arteries. The peripheral lung fields are unusually clear in both. Case 1 . 


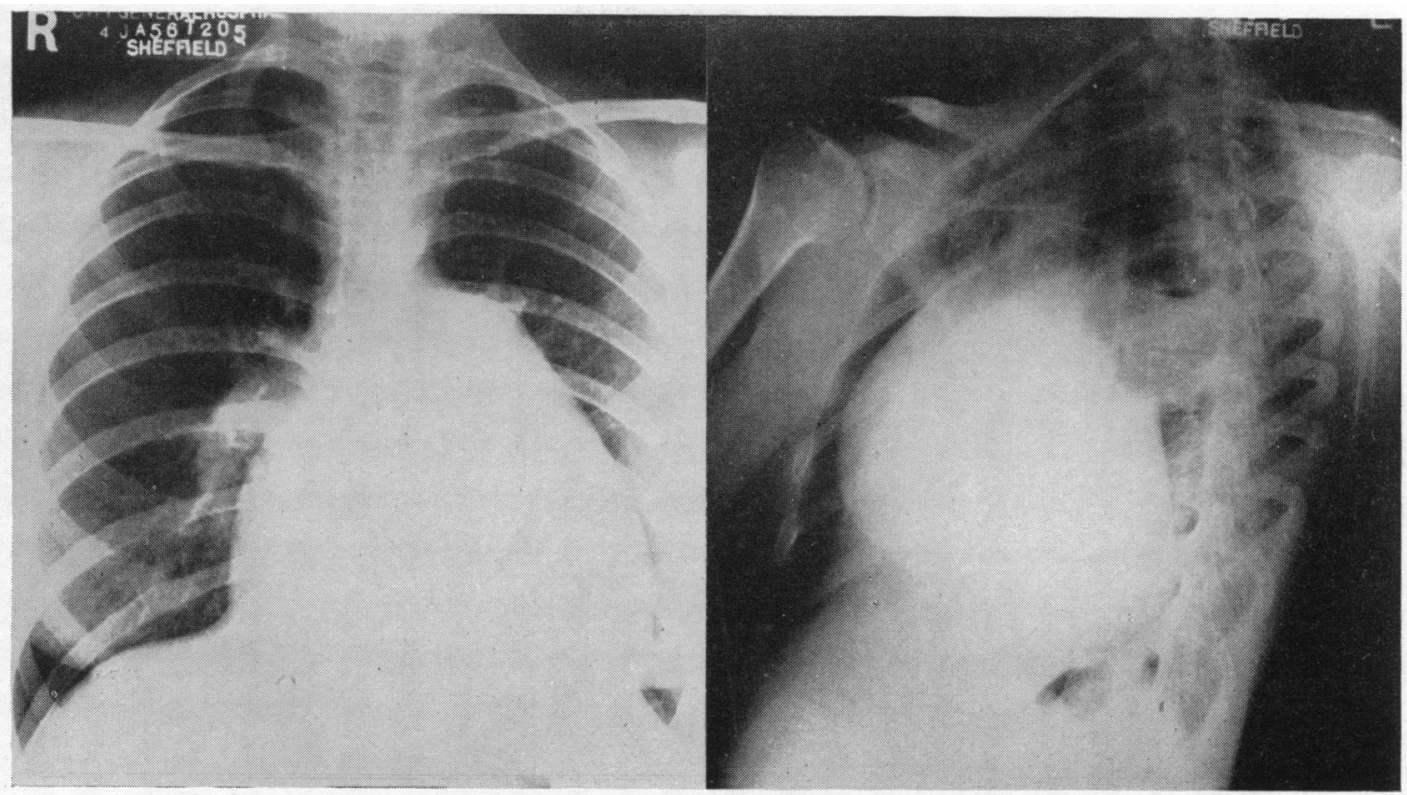

Fig. 3.-P-A teleradiogram and L.A.O. radiogram of the chest. The P-A view shows overall cardiac enlargement with prominence of the pulmonary trunk and its main branches. The peripheral lung fields are unusually clear. In the oblique view there is unusual prominence of the anterior border suggesting right ventricular hypertrophy. The overlapping of the spine by posterior border is suggestive of left ventricular hypertrophy. Case 4.

none was the media taken to be hypertrophied as in none did its thickness exceed 15 per cent of the external diameter of the vessel (Fig. 5). In Cases 1, 2, and 3 the weight of the heart was increased, due to right ventricular hypertrophy. The right chambers of the heart and the pulmonary artery were dilated. In each instance there was atheroma of the pulmonary arterial tree.

Other features of each case are described separately.

Case 1. A woman, aged 45 years, with three children, who had been well until a year before, was admitted for breathlessness on exertion. A few weeks later she developed jaundice, ascites, and bilateral swelling of the ankles. She appeared slightly cyanosed and jaundiced and had the type of brown pigmentation on the face, especially on the forehead, that is generally associated with tricuspid disease. The systemic blood pressure was $140 / 90 \mathrm{~mm}$. The jugular venous pressure was raised about $14 \mathrm{~cm}$. above the sternal angle and showed striking pulsation with a prominent $a$ wave and a rapid $x$ descent. At the mitral area a soft first sound was obscured by a systolic murmur which was followed by second and third heart sounds. At catheterization the pressures were: pulmonary artery $110 / 70 \mathrm{~mm} . \mathrm{Hg}$ (mean 80), right ventricle $110 / 15$ (mean 60), and right atrium 22/18 (mean 20). The hæmoglobin content was $14.2 \mathrm{~g}$. per $100 \mathrm{ml}$. At autopsy the heart weighed $330 \mathrm{~g}$. The thickness of the wall of the infundibulum of the right ventricle was $8 \mathrm{~mm}$. and that of the sinus of the right ventricle $10 \mathrm{~mm}$. The left ventricle was of normal size, its wall being $12 \mathrm{~mm}$. thick.

Case 2. A boy, aged 13 years, complained of breathlessness on exertion, abdominal pain, and fainting attacks for only four months. There was no history of rheumatic fever. On examination he was not cyanosed. A loud systolic murmur was best heard in the third left intercostal space. The hæmoglobin level was $18.4 \mathrm{~g}$. per $100 \mathrm{ml}$. At catheterization the pulmonary artery mean blood pressure was $70 \mathrm{~mm}$. $\mathrm{Hg}$. A month later he developed congestive cardiac failure and cyanosis. In spite of treatment with mercurial diuretics and paracentesis thoracis and abdominis on numerous occasions, he died two years after the onset of symptoms.

Case 3. A girl, aged 12 years, was admitted in congestive cardiac failure. At the age of 5 she developed breathlessness on exertion and became cyanosed. On examination there was cyanosis and finger clubbing. The systemic blood pressure was $130 / 80 \mathrm{~mm}$. In the mitral area there was a thrill and a harsh systolic murmur, and in the pulmonary area the loud second sound was followed by a Graham Steell murmur. 
Cardiac catheterization was not performed. There was a disappointing response to mersalyl therapy and the patient, while still suffering from congestive cardiac failure, died suddenly.

The muscular pulmonary arteries $(100-1000 \mu)$ were also grossly abnormal and showed healing medial necrosis (Fig. 5). In many vessels there were gaps up to $200 \mu$ in length in the media while in others there was loss of continuity of only the external elastic membrane. The lumen of many vessels was partially occluded by fibroelastic tissue which also occupied the gaps in the media to join with tubercles of fibrous tissue that bulged out into the lung parenchyma from the adventitia. The nuclei in the fibrous tissue in the medial deficiencies showed an unusual streaming effect with the long axes of the nuclei running in a radial direction. The adventitial tubercles, up to $400 \mu$ in diameter, consisted of loose cellular fibrous tissue containing many capillaries but no giant cells. The overall appearance was similar to that of the healing stage of periarteritis nodosa.

Case 4. A woman, aged 21 years, was admitted in congestive cardiac failure. At the age of 14 she began to get breathless on exertion and suffer from syncopal attacks. Her dyspnca was progressive, and two years before admission she developed ankle swelling. There was no history of hæmoptysis but her 

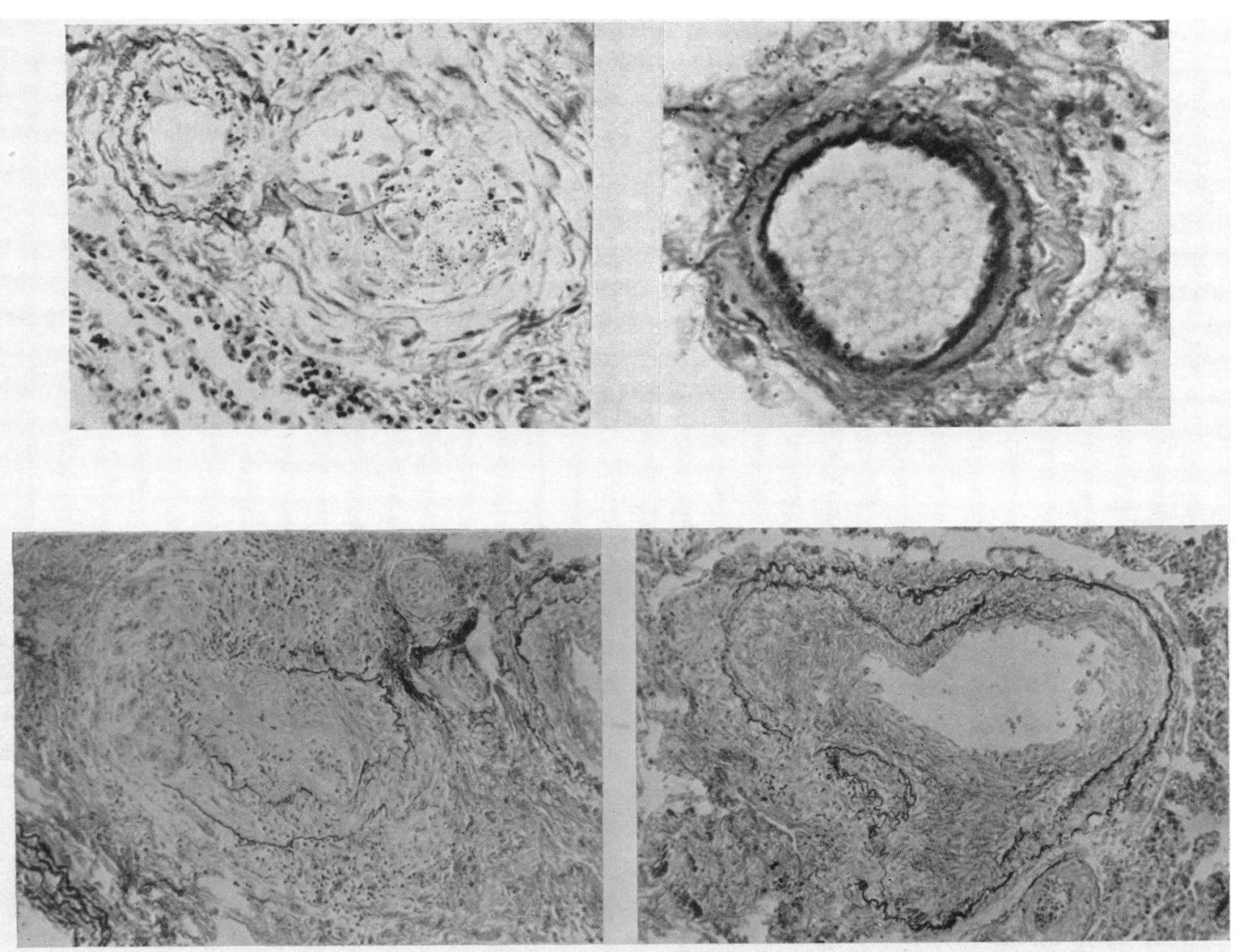

FIG. 5.-Upper left. Transverse section of puimonary arteriole. The vessel is abnormal with a distinct muscular media between two elastic laminæ. Intimal fibrosis partially occludes the lumen. One sector of the vessel wall is necrotic and near this area is an adventitial mass of fibrous tissue. (Verhoeff/van Gieson's stains, $\times 300$.) Case 3. Upper right. Transverse section of pulmonary arteriole. The vessel is abnormal with a distinct muscular media between two elastic laminæ. (Verhoeff/van Gieson's stains, $\times 500$.) Case 2. Lower left. Transverse section of a muscular pulmonary artery. The media is necrotic and, while the internal elastic membrane can still be faintly seen around the entire circumference of the vessel, the faint external elastic membrane can be distinguished only in one sector of the vessel. The medial necrosis appears to have been subacute and extensive organization by fibrous tissue has occurred. The vessel is totally occluded by fibrous tissue and there is extensive adventitial fibrosis. There has been organization in the necrotic areas of the media. (Verhoeff/van Gieson's stains, $\times$ 52.) Case 3. Lower right. Transverse section of a muscular pulmonary artery. This vessel also shows organization following medial necrosis and the appearances are similar to the healing stage of periarteritis nodosa. In this case the changes are less severe. The lumen of the vessel is only partially occiuded by fibrous tissue and the elastic membranes can be seen distinctly over a much wider area. (Verhoeff/van Gieson's stains, $\times$ 52.) Case 3 .

friends had noticed that her voice was hoarse and that she appeared sunburned even in winter. On examination, her voice was hoarse and she had facial pigmentation and slight icterus but no central cyanosis. The systemic blood pressure was $100 / 80 \mathrm{~mm}$. At the apex there was a presystolic triple rhythm and a systolic murmur which was conducted to the tricuspid area. Catheterization demonstrated the following blood pressures (Fig. 4): right atrium $25 / 15 \mathrm{~mm}$. Hg (mean 20), right ventricle 150/20 mm. (mean 70), right pulmonary artery $145 / 85 \mathrm{~mm}$. (mean 100), and pulmonary capillary $15 \mathrm{~mm}$. (mean). The femoral artery blood pressure was $95 \mathrm{~mm}$. The femoral artery blood oxygen saturation was 97 per cent and the mixed venous blood oxygen saturation was 50 per cent. The hæmoglobin level was $14.8 \mathrm{~g}$. per $100 \mathrm{ml}$. and the hæmatocrit was 54 per cent. A renal clearance test demonstrated the renal plasma flow to be $99 \mathrm{ml} . / \mathrm{min}$. and the glomerular filtration rate $47 \mathrm{ml} . / \mathrm{min}$. Respiratory function tests were normal. 


\section{DisCUSSION}

Most of the reported cases of idiopathic pulmonary hypertension have been in young females. Case 2 of the present series and the patient reported by Brinton (1950) were male. Dresdale et al. (1951) stated that the disease has been reported at ages varying from 20 months (Cross and Kobayshi, 1947) to 80 years (McCallum, 1931).

Symptoms. Breathlessness on exertion, chest pain of anginal type, cough, blueness of the lips and nails, and abdominal distension and ankle swelling, due to congestive heart failure, are common symptoms in patients with idiopathic pulmonary hypertension. Hæmoptysis, hoarseness, syncopal attacks, palpitation, and jaundice occur less frequently. Most of these symptoms also occur in patients with other diseases where there is severe pulmonary hypertension so that they appear to be characteristic of this complication and are probably related to the anatomical abnormalities induced in the pulmonary vessels by the raised blood pressures. Breathlessness on exertion was the dominant symptom in all the present patients and in those described by previous authors. From a histological study of the pulmonary arteries in a child of 11 months with Eisenmenger's complex Edwards (1953) believed that the onset of dyspnœa was related to the development in the pulmonary arteries of intimal changes caused by the pulmonary hypertension. It seems possible that the progressive dyspnœa that occurs with other types of heart disease associated with pulmonary hypertension including idiopathic pulmonary hypertension is also due to anatomical changes in the pulmonary vessels which occur in the pulmonary vessels in all these patients.

Although hæmoptysis is another symptom that is characteristic of severe pulmonary hypertension and has been described in patients with idiopathic pulmonary hypertension (Dresdale et al., 1951), it is not common in this disease, and did not occur in any of the present patients. It is possible, as suggested by Wood (1952), that the thin-walled pulmonary capillaries and veins are protected from the high pulmonary artery blood pressures by the anatomical changes that develop in the pulmonary arterioles and muscular pulmonary arteries in this condition.

A history of chronic cough and colds is very characteristic of patients with idiopathic pulmonary hypertension and was obtained in all the present series. These symptoms commonly occur with other diseases associated with pulmonary hypertension. Evans (1951) believed that a frequent cough was a factor that caused the disease to progress, since he thought that the rise in pulmonary artery blood pressure with coughing accelerated the development of intimal fibrosis over areas of medial aplasia and hypoplasia in the muscular pulmonary arteries.

Syncopal attacks have been reported in patients with idiopathic pulmonary hypertension (Wood, 1952; and Branwood, 1954) and these were associated with palpitation in patients reported by Werkö and Eliasch (1952) and Dresdale et al. (1951).

Although chest pain occurred in none of the present series it is a common symptom in patients with idiopathic pulmonary hypertension (Wood, 1952; Gilmour and Evans, 1946; and Branwood, 1954). Like dyspnœa, this symptom occurs in other forms of congenital heart disease associated with pulmonary hypertension (Hultgren et al., 1953). Dresdale et al. (1951), although they found no associated coronary disease, thought that the chest pain was due to the coronary blood flow being insufficient for the degree of right ventricular hypertrophy in these patients, because it resembled angina pectoris so closely. Viar and Harrison (1952) noted that nitroglycerine had no effect on the chest pain associated with pulmonary hypertension and suggested that it was due to distension of the main pulmonary arteries.

Brinton (1950) described a man of 26 years with idiopathic pulmonary hypertension who had lost his voice due to paralysis of the left vocal cord which was probably caused by pressure on the recurrent laryngeal nerve by the grossly dilated pulmonary arteries. This type of hoarseness has also been reported in other patients with presumed severe pulmonary hypertension and extreme dilatation of the pulmonary arteries (Baumgartner and Abbott, 1929; and Millman and Kornblum, 1936).

Congestive cardiac failure is the usual terminal stage of idiopathic pulmonary hypertension. Although jaundice and facial pigmentation, which occurred as presenting symptoms in our Case 1, 
have not been stressed in previous reports these signs might be expected to develop commonly as complications of congestive heart failure. They are probably manifestations of Shattuck's sign and are caused by hepatic distension associated with tricuspid incompetence.

Signs. The physical signs are those of right ventricular hypertrophy and pulmonary hypertension. In a recent review Bedford (1951) described a systolic impulse sometimes with a thrill, followed by a diastolic click corresponding to the second sound, palpable in the second and third left interspaces, a duplicated second sound, frequently a systolic murmur, occasionally a Graham Steell murmur, displacement of the apex beat to the left, a diffuse cardiac impulse, a triple rhythm and, later, signs of tricuspid incompetence as the important clinical signs of pulmonary hypertension: Wood (1952) has emphasized the diagnostic importance of giant $a$ waves in the jugular venous pulse of patients with idiopathic pulmonary hypertension. Although many authors have commented only on the loudness of the second sound in the pulmonary area in patients with pulmonary hypertension, in the present series there was close splitting of the loud second sound in the pulmonary area such as was noted by Wood (1952). Although these signs are characteristic of idiopathic pulmonary hypertension they are not pathognomic of this disease since they have been described in patients with severe pulmonary hypertension complicating mitral stenosis or right-to-left shunts and constitute a group that Heath and Whitaker (1956) have termed hypertensive pulmonary disease.

Cyanosis occurs commonly as a terminal feature and in the absence of an intracardiac shunt has usually been considered to be of peripheral origin. However, Ordway (1952) found arterial oxygen unsaturation in a patient with idiopathic pulmonary hypertension during inhalation of pure oxygen which suggests that the anatomical changes in the small pulmonary vessels may sometimes cause impairment of aeration of the pulmonary arterial blood. All three patients in the present series appeared cyanosed but in those where the arterial blood oxygen was estimated, normal values were obtained.

There are no cardiac murmurs characteristic of idiopathic pulmonary hypertension. In the present series an apical systolic murmur occurred in all four cases, a basal systolic murmur in Case 2, and a Graham-Steell murmur in Case 3 but, as pointed out by Whitaker et al. (1955) these auscultatory signs are indistinguishable from those occurring when severe pulmonary hypertension complicates other congenital anomalies. In the terminal stage of idiopathic pulmonary hypertension congestive heart failure and tricuspid incompetence have been commonly noted and occurred in all the present cases. At this stage jaundice and pigmentation of the face may appear as in our Cases 1 and 4.

Wood (1952) considers that in idiopathic pulmonary hypertension the peripheral pulse is small and the blood pressure rather low with the systolic and diastolic pressure approaching the mean. In our Case 4 the radial pulse was of poor volume and the systemic blood pressure was 100/80, which was lower than the pulmonary artery blood pressure.

Electrocardiography. The electrocardiogram shows evidence of right ventricular hypertrophy and usually there is also evidence of right atrial hypertrophy (Howarth et al., 1947; and Wood, 1952) (Fig. 1). While these signs are characteristic of idiopathic pulmonary hypertension they are not pathognomonic of it since, like many of the symptoms and signs, they occur with mitral stenosis and right-to-left shunts complicated by severe pulmonary hypertension.

Radiology. In patients with idiopathic pulmonary hypertension radiological examination usually shows dilatation of the pulmonary artery and its main branches with increased pulsation not amounting to a hilar dance, abnormally clear peripheral lung fields, and cardiac enlargement that is due to right ventricular hypertrophy but may suggest left ventricular hypertrophy, as in Cases 1 and 4 (Fig. 3). These features are found in other forms of heart disease complicated by severe pulmonary arterial hypertension and often mask other abnormal radiological signs that occur with these diseases (Brown et al., 1955; Whitaker et al., 1955; and Heath et al., 1956). It is impossible to differentiate idiopathic pulmonary hypertension from ventricular septal defect, atrial septal defect, or patent ductus with pulmonary hypertension by examination of teleradiograms. 
Patients with mitral stenosis with severe pulmonary hypertension, who may show clinical and cardiographic features identical with those of idiopathic pulmonary hypertension can usually be distinguished on radiological examination by the degree of left atrial enlargement, pulmonary hæmosiderosis, and horizontal lines at the lung bases due to lymph stasis (Whitaker and Lodge, 1954).

Angiocardiography. As in all patients with severe pulmonary hypertension, angiocardiography demonstrates dilated main pulmonary arteries and a coppicing effect in the peripheral lung fields (Fig. 2). This method is not of diagnostic importance in patients with idiopathic pulmonary hypertension unless they have central cyanosis when demonstration of the absence of an abnormal shunt from the right chambers of the heart excludes conditions such as patent ductus, atrial septal defect, and ventricular septal defect with reversal of flow.

Cardiac Catheterization. In patients with idiopathic pulmonary hypertension who have been studied by catheterization (Howarth et al., 1947; Dresdale et al., 1951; Werkö and Eliasch, 1952; and Wood, 1952) it has been possible to demonstrate severe pulmonary arterial hypertension (Fig. 4), normal pulmonary capillary blood pressure, abnormally high atrial pulse pressures (Fig. 4), normal or only slightly reduced arterial blood oxygen saturation, and abnormally low mixed venous blood oxygen saturation indicating an increased arterio-venous oxygen difference and a low cardiac output. Cardiac catheterization is the most important method of special investigation since it distinguishes patients with congenital cardiac anomalies such as patent ductus, atrial septal defect and ventricular septal defect with severe pulmonary arterial hypertension and balanced shunts who are clinically indistinct from patients with idiopathic pulmonary hypertension. In the anomaly under discussion the blood samples show no evidence of an intracardiac shunt while in these other congenital anomalies, even when the flows appear balanced from clinical examination, it is usual to detect some change in the oxygen saturation of samples from the right side of the heart, and is usually possible to direct the tip of the catheter through a ductus or a septal defect (Whitaker et al., 1955).

Other Investigations. Pulmonary function has not been extensively studied in idiopathic pulmonary hypertension. Dresdale et al. (1951) studied the ventilatory capacity in two of their patients and found it to be normal in one and reduced in the other. In Case 4 of the present series respiratory function was normal. Werkö and Eliasch (1952) found a low glomerular filtration rate and a low renal blood flow in a patient with idiopathic pulmonary hypertension, and these and the renal plasma flow were extremely low, about a sixth of their normal value, in our Case 4.

Pathology. Anatomical abnormalities in the heart and lungs that characterize idiopathic pulmonary hypertension are hypertrophy and dilatation of the right ventricle, dilatation of the tricuspid ring, right atrial hypertrophy, dilatation of the pulmonary valve and main pulmonary arteries, with pulmonary atheroma and specific changes in the small pulmonary vessels. None of these anatomical abnormalities is pathognomonic of idiopathic pulmonary hypertension since all may occur when severe pulmonary hypertension complicates cases with a left-to-right shunt.

The most common abnormality in the small pulmonary blood vessels is a distinct muscular media in the pulmonary arteriole $(<100 \mu$ in diameter), which normally, in the adult, consists of a single elastic lamina lying between intima and adventitia. This abnormality was present in all three cases examined at autopsy in this series, and in Cases 1 and 3 there was also intimal fibrosis leading to occlusion of the lumen of the arterioles. Usually there is also medial hypertrophy in the muscular pulmonary arteries $(100-1000 \mu$ in diameter) and intimal fibrosis which may completely occlude the lumen of these vessels. Medial necrosis sometimes occurs in the muscular pulmonary arteries and pulmonary arterioles and was observed in Cases 1 and 3. These anatomical abnormalities have been described frequently in idiopathic pulmonary hypertension (Howarth et al., 1947; Werkö and Eliasch, 1952; Aitchison and Richmond, 1955; Gilmour and Evans, 1946; and Branwood, 1954) but with the exception of arterial necrosis have been reported equally commonly in other diseases associated with severe pulmonary arterial hypertension.

Differential Diagnosis. The differential diagnosis of the present anomaly is from other cyanotic 
and acyanotic conditions associated with pulmonary hypertension. Cyanosis in idiopathic pulmonary hypertension is rarely so severe as in patients with septal defects, patent ductus, or transposition, associated with pulmonary hypertension in whom the degree of polycythæmia may be so severe as to mimic polycythæmia rubra vera (Whitaker et al., 1955). A long history of recurrent pulmonary infection and signs of pulmonary hypertension and cyanosis may suggest chronic pulmonary heart disease but the absence of carbon-dioxide retention will exclude this diagnosis (Platts and Whitaker, 1954). Since the clinical, radiological, and electrocardiographic features of cases with left-to-right shunts and pulmonary hypertension may be indistinguishable from idiopathic pulmonary hypertension, these lesions are difficult to differentiate from it unless angiocardiography and cardiac catheterization are carried out. Angiocardiograms show no intracardiac shunt in idiopathic pulmonary hypertension but often demonstrate early filling of an overriding aorta in Eisenmenger's complex (Brown et al., 1955), early filling of the descending aorta from the pulmonary artery in patent ductus arteriosus (Whitaker et al., 1955), early filling of the left atrium in atrial septal defect (Whitaker et al., 1955), and early filling of the left ventricle in ventricular septal defect, when these anomalies are associated with pulmonary hypertension of such a degree as to cause reversal of the flow. After studying patients with congenital septal defects complicated by severe pulmonary hypertension, who on clinical, radiological, and cardiographic examination had appeared indistinguishable from patients with idiopathic pulmonary hypertension, the present authors thought that the latter diagnosis could be substantiated only when autopsy proof was available (Whitaker et al., 1955). However, it now seems that cardiac catheterization usually reveals underlying congenital cardiac anomalies, when they are present, and that, if at this investigation it has not been possible to pass the catheter through a ductus or a septal defect or to demonstrate an intracardiac shunt from an examination of the oxygen saturation of the blood samples from the heart, idiopathic pulmonary hypertension may generally be diagnosed.

Prognosis and Treatment. Although patients may have symptoms of breathlessness for many years, as in Case 4 of the present series, the disease runs a malignant course after the onset of congestive cardiac failure and death usually occurs within two years, as in the other cases of this series and in the patient reported by Aitchison and Richmond (1955).

No treatment that has any significant influence on the course of idiopathic pulmonary hypertension has been described. Repeated oxygen inhalation (Motley et al., 1947; Swan and Wood, 1954) and antispasmodics, especially priscoline (Dresdale et al., 1951) have been used in attempts to overcome any possible pulmonary vascular spasm. However, it seems unlikely that such treatment can alleviate a disease that is characterized by severe abnormalities in the small pulmonary blood vessels which, on histological appearances, appear to be irreversible. Prolonged anticoagulant therapy suggested by Cutler et al. (1954) seems unlikely to have any effect on the disease since most of the pulmonary blood vessels are totally occluded by proliferation of intimal fibro-elastic tissue not secondary to thrombi. Furthermore, in patients who have had severe hæmoptyses it may be dangerous. There is no satisfactory surgical treatment for idiopathic pulmonary hypertension and it should be regarded as a fatal disease characterized by irreversible occlusive changes in the small pulmonary blood vessels not amenable to any form of treatment.

\section{SUMMARY}

One boy, one girl, and two women with idiopathic pulmonary hypertension are described. The diagnosis was confirmed at autopsy in three and the other is still alive.

The symptoms and signs associated with this anomaly are characteristic but not pathognomonic since they occur in other forms of heart disease with severe pulmonary hypertension. Breathlessness on exertion, chest pain of anginal type, cough, blueness of the lips and nails, and abdominal distension and ankle swelling due to congestive cardiac failure are common symptoms in patients with idiopathic pulmonary hypertension. Hæmoptysis, hoarseness, syncopal attacks, palpitation, and jaundice occur less frequently. 
The only physical signs common to the group of patients are those of pulmonary hypertension and congestive cardiac failure. There is always electrocardiographic evidence of right ventricular dominance.

On radiological examination there is moderate to great cardiac enlargement, dilatation of the pulmonary artery and its main branches, and clear peripheral lung fields. These features are not sufficiently characteristic to distinguish them from severe pulmonary hypertension complicating other cardiac anomalies.

Angiocardiography is of diagnostic importance only when there is central cyanosis. Cardiac catheterization is considered the most important diagnostic investigation since it demonstrates the absence of intracardiac shunts.

The pathological features and histological abnormalities in the small pulmonary blood vessels in three cases are described.

We acknowledge the facilities of the Radiological Department, City General Hospital, given by Miss E. K. Abbott, Consultant Radiologist. We wish to thank Miss N. Hardy and Mr. C. Lambourne for technical assistance.

\section{REFERENCES}

Aitchison, J. D., and Richmond, H. G. (1955). Brit. Heart J., 17, 312.

Baumgartner, E. A., and Abbott, M. E. (1929). Amer. J. med. Sci., 177, 639.

Bedford, D. E. (1951). Proc. Roy. Soc. Med., 44, 597.

Branwood, A. W. (1954). Edin. med. J., 61, 332.

Brinton, W. D. (1950). Brit. Heart J., 12, 305.

Brown, J. W., Heath, D., and Whitaker, W. (1955). Brit. Heart J., 17, 273.

Cross, K. R., and Kobayshi, C. K. (1947). Amer. J. Clin. Path., 17, 155.

Cutler, J. G., Nada, A. S., Goodale, W. T., Hickler, R. B., and Rudolph, A. M. (1954). Amer. J. Med., $17,485$.

Dresdale, D. T., Schultz, M., and Michtom, R. J. (1951). Amer. J. Med., 11, 686.

Edwards, J. E. (1953). Pathology of the Heart. Edited by Gould, S. E. Thomas, Springfield, Illinois.

Evans, W. (1951). Proc. Roy. Soc. Med., 44, 600.

Gilmour, J. R., and Evans, W. (1946). J. Path. Bact., 58, 687.

Heath, D., Brown, J. W., and Whitaker, W. (1956). Brit. Heart J., 18, 1.

- - and Whitaker, W. (1956). Medicine (submitted).

Howarth, S., McMichael, J., and Sharpey-Schafer, E. P. (1947). Brit. Heart J., 9, 292.

Hultgren, H., Selzer, A., Purdy, A. Holman, E., and Gerbode, F. (1953). Circulation, 8, 15.

McCallum, W. G. (1931). Bull. Johns Hopkins Hosp., 49, 37.

Millman, S., and Kornblum, D. (1936). J. Tech. Methods, 15, 147.

Motley, H. L., Cournard, A., Werkö, L., Himmelstein, A., and Dresdale, T. (1947). Amer. J. Physiol., $150,315$.

Ordway, N. A. (1952), Remarks made at the Annual Meeting of the Society for Paediatric Research, Atlantic City, N.J. Quoted by Cutler et al. (1954).

Platts, M. M., and Whitaker, W. (1954). Amer. Heart J., 48, 77.

Swan, H. J. C., and Wood, E. H. Unpublished data quoted in Swan, H. J. C., Zapata-Diaz, J., Burchell, H. B., and Wood, E. H. (1954). Amer. Med., 16, 12.

Viar, W. N., and Harrison, T. R. (1952). Circulation, $5,1$.

Werkö, L., and Eliasch, H. (1952). Cardiologica, 21, 403.

Whitaker, W., Heath, D., and Brown, J. W. (1955). Brit. Heart J., 17, 121.

, and Lodge, T. (1954). J. Fac. Radiol., 5, 182.

Wood, P. (1952). Brit. med. Bull., 8, 348. 